\title{
Problems with anti-clotting drug
}

\section{- First-year sales only half of projected values - Accusations of withheld information \\ Advantages over competitors not clear-cut}

Berkeley

STORM clouds have gathered over Genentech's new clot-dissolving drug, Activase (the company's trade name for tissue plasminogen activator, TPA). News that TPA sales are lower than expected have the South San Francisco company's stock price plunging. Now, questions have arisen over the ethics of the company's promotion and testing of the drug.

Seven class-action lawsuits have been filed against Genentech, on behalf of stockholders claiming that the company withheld adverse information about TPA's promise while company insiders sold off $\$ 24$ million in shares. In addition, staff of a congressional committee have discovered that at least fifteen of the researchers participating in trials of TPA owned Genentech stock.

Activase was greeted with fanfare when it was released last November, and sales of the drug amounted to $\$ 58$ million by the end of December. Although the alternative drug, streptokinase, had been available for some time, TPA's expected advantages, such as greater clot specificity and fewer allergic or bleeding side-effects, promised to help it to obtain a large share of the thrombolytic drug market, despite its price of $\$ 2,200$ a dose, eleven times that of the less glamorous streptokinase.

With first-year sales projected at about $\$ 180$ million, TPA will be the most successful first-year drug ever. But sales have nevertheless fallen short of predictions roughly twice as great, and the price of Genentech stock has fallen by a half since the beginning of the year. Company officials have blamed TPA's slower-thanexpected start on physicians' confusion over trial data rather than company overenthusiasm for its product.

Indeed, there is little agreement among cardiologists about the meaning of the various trials of TPA and its competitors, indicating that TPA's advantages are less clear-cut than enthusiasts expected. The lack of a large head-to-head mortality trial comparing TPA and streptokinase complicates the comparison.

The result is that cardiologists find support for opposing views by dipping into the same pool of data. TPA supporters say the drug is significantly better at clearing arteries when administered during the critical first four hours after a heart attack, and carries a lower risk of recurrent blockage or internal bleeding. But TPA opponents use the same studies to conclude that the drug is not significantly better than streptokinase, and carries higher re-blockage and bleeding risks.

The recent lawsuits accuse Genentech of withholding the drug-trial ambiguities from investors, but Denise Gilbert, a market analyst with Montgomery Securities in San Francisco, says the charges are unlikely to stick, because analysts knew of the trial results as soon as the medical community.

But in spite of the confusing results, many analysts believed Genentech's insistence that TPA would be the drug of choice for heart attacks. Although reluctant to fault Genentech for what they

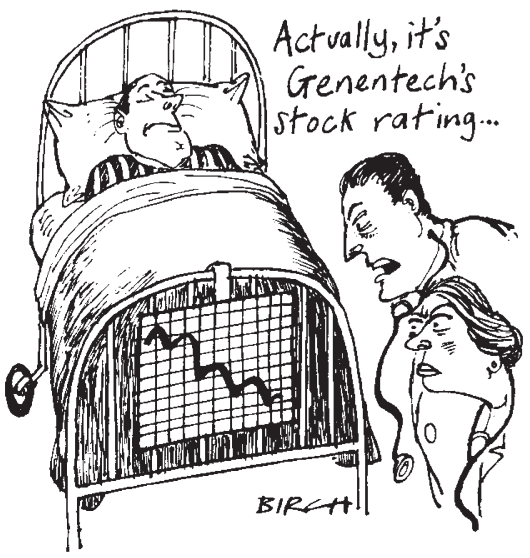

describe as a "brilliant" marketing campaign, some now feel manipulated or misled.

Genentech reported last April that TPA use was growing, and had reached 2,000 doses a week, up from 1,000 at the beginning of the year. Then, according to Gilbert, they stopped talking about patient numbers. In July there was news that sales were lower than predicted, but that was attributed by company officials to over-stocking by hospitals and suppliers when the drug first came out, and analysts such as Gilbert expected sales to bounce back as the surplus shrank and usage grew. So they were shocked to learn in September that TPA usage had remained constant since April. Two weeks later, Genentech announced suspension of TPA production, because of a surplus created during the first half of the year.

Gilbert questions why the company's July announcement did not mention that TPA usage had been flat since April. Moreover, it cannot have been constant at the claimed rate of 2,000 patients a week, she says, because the company is now saying the total number of patients treated with TPA since last November is 50,000 , a number more consistent with a usage rate of $1,000-1,200$ a week.

Genentech denies intentionally making over-optimistic sales forecasts, and has refused to comment on the lawsuits, beyond a statement that they contain "numerous factual inaccuracies" and that the company plans to defend them "vigorously".

Some observers of the biotechnology industry say the over-optimism was generated as much by enthusiastic cardiologists as by Genentech's marketing. But evidence gathered by the staff of the House of Representatives government operations subcommittee on human resources and intergovernmental relations revealed that at least 15 researchers participating in TPA trials owned stock in Genentech. The subcommittee staff investigation has also revealed that Genentech offered options to buy sizeable amounts of its stock to three additional researchers, including one who was a member of the executive committee of the Thrombolysis in Myocardial Infarction (TIMI) trial sponsored by the National Institutes of Health.

At a human resources subcommittee hearing on 29 September, a member of the TIMI monitoring committee testified that committee members seemed strongly biased towards TPA before the trial even began. Victor Marder, co-chief of haematology at the University of Rochester, said an atmosphere of urgency drove the committee to begin a second phase mortality trial before results from a preliminary trial comparing TPA to streptokinase had been adequately analysed. He said committee members seemed so convinced that TPA was better that they dropped streptokinase from the more extensive mortality phase of the trial, thus eliminating an opportunity for a direct comparison of the drugs.

TPA supporters staunchly argue that it is more effective and safer than its competitors. But some, weary of the debate, say either drug can save lives, and placing politics ahead of medicine has scared away conservative cardiologists, so that only a fraction of the several hundred thousand heart-attack victims who stand to benefit from the drugs are receiving them. "The death rate from acute MI has been cut in half by thrombolysis when implemented early", said Burton Sobel, director of the cardiovascular division at Washington University, and a consultant to Genentech. "We have a truly phenomenal advance, and it's not being used widely in 1988." 